\title{
Quantification of Total Phenolics, Flavonoids and Evaluation of in vitro Free Radical Scavenging Activities in Psidium guajava L.
}

\author{
B. H. SOWMYA* AND D. USHA ANANDHI ${ }^{1}$
}

Research Scholar, Department of Zoology, ${ }^{1}$ Professor, Department of Zoology, Bangalore University, Jnanabharathi, Bangalore-560 056 India

Sowmya et al.: Free radical scavenging activities in Psidium guajava $\mathrm{L}$

\begin{abstract}
The present study was undertaken to quantify total phenolics and flavonoids and investigate in vitro free radical scavenging activities of leaf extracts of two varieties of Psidium guajava L. viz., Lalit and Allahabad safeda. Leaf extracts of Lalit and Allahabad safeda were prepared by Soxhlet extraction and ethanol extracts were used for in vitro assays. Total phenolic and flavonoid contents, 2,2-azinobis(3-ethylbenzothiazoline-6-sulfonic acid), 2,2-diphenyl-1-picrylhydrazyl, nitric oxide and super oxide free radical scavenging activities were determined at 100, 200, 300, 400, 500, 600 and $700 \mu \mathrm{g} /$ ml concentrations of Lalit and Allahabad safeda leaf extracts. Results indicated the presence of higher phenolic and flavonoid contents in the leaf extract of Lalit compared to that of Allahabad safeda. The leaf extracts of Lalit and Allahabad safeda showed dose-dependent increase in 2,2-azino -bis(3-ethylbenzothiazoline-6-sulfonic acid), 2,2-diphenyl-1-picrylhydrazyl and nitric oxide radical scavenging activities and a decrease in super oxide radical scavenging activities. However, Lalit showed higher free radical scavenging activity compared to that of Allahabad safeda. Further, the $\mathrm{IC}_{50}$ values of Psidium guajava for DPPH, 2,2-azino-bis(3-ethylbenzothiazoline-6-sulfonic acid), nitric oxide and super oxide free radicals were $229.56,503.07,430.40,07$ and $377.96 \mu \mathrm{g} / \mathrm{ml}$, respectively. In addition, the $\mathrm{IC}_{50}$ values of Allahabad safeda for 2,2-diphenyl-1-picrylhydrazyl, 2,2-azino-bis(3-ethylbenzothiazoline6-sulfonic acid), nitric oxide and super oxide free radicals were, 270.24, 543.63, 469.99 and $515.50 \mu \mathrm{g} / \mathrm{ml}$, respectively. This study clearly demonstrated antioxidant activity in both the extracts of Lalit and Allahabad safeda. The better antioxidant activity of Lalit extract could be due to the presence of higher phenolic content compared to Allahabad safeda.
\end{abstract}

Key words: ABTS, antioxidant, DPPH, free radicals, nitric oxide, superoxide

Free radicals are reactive molecules involved in many physiological processes and have been associated with diabetes, cancer, arthritis and liver injury ${ }^{[1]}$. Cellular antioxidant enzyme system has the capacity to scavenge free radicals in the body ${ }^{[2,3]}$. Antioxidants are compounds that can delay the oxidation of other molecules by inhibiting the initiation or propagation of oxidation chain reactions caused by free radicals and thereby reduce oxidative damage to the body ${ }^{[4]}$. Antioxidants are classified into enzymatic and nonenzymatic antioxidants based on their activity. The enzymatic antioxidants convert oxidized metabolic products in to hydrogen peroxide and then to water using cofactors such as, iron, zinc, copper and manganese. However, non-enzymatic antioxidants intercept and

*Address for correspondence E-mail: sowmyaarasu7@gmail.com terminate free radical chain reactions. Vitamin E, $\mathrm{A}$ and $\mathrm{C}$, flavonoids, carotenoids, glutathione, plant polyphenols, uric acid, theaflavin, allyl sulfides, curcumin, melatonin, bilirubin and polyamines are some examples of natural non-enzymatic antioxidants. The examples of enzymatic antioxidants are superoxide dismutase (SOD), catalase (CAT) and glutathione peroxidase (GPx). The antioxidants are either watersoluble or lipid-soluble and predominantly found in

This is an open access article distributed under the terms of the Creative Commons Attribution-NonCommercial-ShareAlike 3.0 License, which allows others to remix, tweak, and build upon the work non-commercially, as long as the author is credited and the new creations are licensed under the identical terms

Accepted 14 July 2020

Revised 09 May 2020

Received 25 February 2020

Indian J Pharm Sci 2020;82(4):578-585 
cytosol, cytoplasmic matrix and cell membranes. The antioxidant components are composed of lipid-soluble and water-soluble substances. Plant-based antioxidants are mostly hydrophilic such as phenolics, flavonoids, SOD, CAT, GPx, uric, lipoic, benzoic and ascorbic acids. On the other hand, hydrophobic antioxidants are linked to carotenoids, tocopherols, vitamin $\mathrm{K}$, ubiquinone and phospholipids.

Drugs with antioxidant properties have been used since few decades for the treatment of various disorders ${ }^{[5]}$. However, these synthetic drugs have been suspected to cause negative side effects. Hence, there is a growing trend in the modern day studies to substitute synthetic drugs with herbal extracts containing antioxidants.

Plants have been used as medicinal remedies for centuries throughout the world. The secondary metabolites produced in the plants have antioxidant properties, which are important to protect cells from damage caused by free radicals and exert protection against cellular oxidation reaction ${ }^{[6,7]}$. Several studies reported antioxidant properties of different plant extracts and their phytochemicals ${ }^{[8,9]}$.

The present study focused on important Indian herb Psidium guajava L. commonly known as Guava for its antioxidant property. It belongs to the family Myrtaceae. P. guajava is considered to be highly nutritious due to the presence of high level of dietary fiber, vitamin A and $\mathrm{C}$, folic acid, potassium, copper and manganese. The leaves of $P$. guajava contain more terpenoids and possess different pharmacological properties such as anticancer, antimicrobial ${ }^{[10,11]}$, antioxidant ${ }^{[12]}$, anticough $^{[13]}$, antidiabetic ${ }^{[14]}$ and antimutagenic ${ }^{[15,16]}$. In addition, the leaf extract is known to have tranquilizing effect on intestinal smooth muscle and inhibit chemical processes during diarrhoea and aid in the reabsorption of water in intestine ${ }^{[17]}$.

Natural antioxidants can protect the body from free radicals and retard the progress of many chronic diseases. Many previous reports indicated the usage of large number of herbal extracts against various diseases, in which reactive oxygen species and free radicals play a vital role ${ }^{[18]}$. Different natural substances, flavonoids, tannins, coumarins and procyanidins have been shown to scavenge free radicals and therefore considered as promising therapeutic agents ${ }^{[19]}$. Therefore, there is a keen interest on exogenous antioxidants from natural sources due to their easy availability, lesser side effects and effectiveness ${ }^{[20]}$. Though there are few studies on antioxidant properties of $P$ guajava, there are no studies involving comparative analysis of free radical scavenging activity of the two varieties of $P$. guajava L., Lalit (LA) and Allahabad safeda (AS) in vitro.

Hence, present study was taken up to investigate the free radical scavenging activity of these two varieties of $P$. guajava L. in order to understand which variety is more effective. In addition to its nutritional value, the present study would provide an insight to identify antioxidant molecules from the leaf extracts $P$. guajava L. to study the beneficial effects in treatment of different disorders.

\section{MATERIALS AND METHODS}

Different chemicals, 2,2-azino-bis(3ethylbenzothiazoline-6-sulfonic acid) (ABTS), 2,2-diphenyl-1-picrylhydrazyl (DPPH), 3-(2-pyridyl)5,6-diphenyl-1,2,4-triazine-4',4"'disulfonic acid, potassium ferricyanide, catechin, ascorbic acid, tannic acid, Folin-Ciocalteau phenol reagent and sodium carbonate were purchased from Sigma Chemical Co. (St. Louis, MO, USA). All the chemicals used in were of analytical grade.

\section{Plant material and preparation of leaf extract:}

Fresh leaves of the two varieties of P. guajava L., AS and LA were collected from the Regional Horticultural Research and Extension Centre, UAS campus GKVK, Bengaluru (longitude of $77^{\circ} 56^{\prime} \mathrm{E}$ and latitude of $13^{\circ} 9^{\prime}$ $\mathrm{N}$ and 942.37, Acc. No: RRCBI-18272).

Fresh leaves of AS and LA were washed with distilled water and shade-dried at room temperature $\left(27 \pm 2^{\circ}\right)$ for 40-45 d. Leaves were powdered using a mechanical blender and subjected to Soxhlet extraction. The extraction procedure was repeated successively with solvents of increasing polarity, petroleum ether, benzene, chloroform and ethanol. After extraction, the extract was concentrated in a flash evaporator, solvent was recovered and the extract was dried in a desiccator. Among the four different solvent extracts, the ethanol extract was found to be more effective and hence the same was used in the present study.

\section{Quantification of phytochemical constituents:}

The total phenol content in the leaf extract was determined using modified Folin-Ciocalteu method ${ }^{[21]}$. An aliquot $(0.5 \mathrm{ml})$ of leaf extract (1:5 dilution) was mixed with $0.1 \mathrm{ml}$ of Folin-Ciocalteau reagent 
$(0.5 \mathrm{~N})$ and incubated at room temperature for $15 \mathrm{~min}$. The mixture was further incubated for $30 \mathrm{~min}$ at room temperature after adding $2.5 \mathrm{ml}$ saturated sodium carbonate. The absorbance was measured at $760 \mathrm{~nm}$ and the total phenol content was expressed in terms of gallic acid equivalent $(\mathrm{GAE} \mathrm{mg} / \mathrm{g}) . \mathrm{C}=(\mathrm{c} \times \mathrm{vm}) / \mathrm{m}$, where, $\mathrm{C}=$ total phenol content in terms of $\mathrm{mg}$ of gallic acid equivalents/g extract, $\mathrm{c}=$ concentration of gallic acid established from the calibration curve $(\mathrm{mg} / \mathrm{ml})$, $\mathrm{v}=$ volume of extract in $\mathrm{ml}, \mathrm{m}=$ weight of extract in gram.

The total flavonoid content in the leaf extracts was determined using the method as reported ${ }^{[22]}$. The $0.5 \mathrm{ml}$ of $2 \%$ aluminium chloride ethanol solution was mixed with $0.5 \mathrm{ml}$ of sample and incubated at room temperature for $1 \mathrm{~h}$. The absorbance was measured at $420 \mathrm{~nm}$ and the total flavonoid content was calculated from standard quercetin curve and results were expressed in terms of quercetin equivalents $(\mathrm{QE} \mathrm{mg} / \mathrm{g}) . \mathrm{C}=(\mathrm{c} \times \mathrm{v}) / \mathrm{m}$, where, $\mathrm{C}=$ total flavonoid content in terms of $\mathrm{mg}$ of $\mathrm{QE} / \mathrm{g}$ extract, $\mathrm{c}$ is the concentration of quercetin established from the calibration curve $(\mathrm{mg} / \mathrm{ml}), \mathrm{v}$ is the volume of extract in $\mathrm{ml}, \mathrm{m}$ is the weight of extract in $\mathrm{g}$.

\section{Antioxidant scavenging activity:}

The ABTS activity of the leaf extracts was determined by following the standard protocol ${ }^{[23]}$. Ascorbic acid and gallic acid were used as the standards. The working solution was prepared by mixing equal amount of $7 \mathrm{mM}$ ABTS solution and $2.4 \mathrm{mM}$ potassium persulphate and was incubated in dark for $12 \mathrm{~h}$ at room temperature. After the incubation, $1 \mathrm{ml}$ of working solution was mixed with $1 \mathrm{ml}$ of the plant extract with different concentration ranging from $100-600 \mu \mathrm{g} / \mathrm{ml}$ and the reaction mixture was vortexed. The absorbance was measured at $734 \mathrm{~nm}$ at 6 min intervals. Percent inhibition capacity of ABTS of the leaf extract was calculated using the formula; \% ABTS scavenging activity $=($ A control-A sample $) / \mathrm{A}$ control $) \times 100$, where, A control is the absorbance of ABTS + ethanol, A sample is the absorbance of ABTS + leaf extract or standard.

The 2,2-diphenyl-1-picrylhydrazyl radical (DPPH) scavenging activity was measured as per the procedure $^{[24]}$. One millilitre of different aliquots of leaf extract $(100-600 \mu \mathrm{g} / \mathrm{ml})$ was mixed with $3 \mathrm{ml}$ of DPPH and the mixture was incubated at $37^{\circ}$ for $30 \mathrm{~min}$. The absorbance was measured at $517 \mathrm{~nm}$ and a decrease in DPPH absorbance indicated an increase in radical scavenging activity. Ascorbic acid was used as the standard and the \% inhibition of DPPH radical scavenging activity was calculated using the formula, $\%$ DPPH scavenging activity=(Abs control-Abs test $) /$ Abs control) $\times 100$, where, Abs control is the absorbance of the control, Abs test is the absorbance of the leaf extract or standard.

Nitric oxide scavenging activity was measured using Griess reaction method ${ }^{[25]}$. One millilitre of $10 \mathrm{mM}$ sodium nitroprusside was mixed with $1 \mathrm{ml}$ of test or standard solution of different concentrations in phosphate buffer ( $\mathrm{pH} \mathrm{7.4)} \mathrm{and} \mathrm{the} \mathrm{mixture} \mathrm{was}$ incubated at $25^{\circ}$ for $150 \mathrm{~min}$. After the incubation $1 \mathrm{ml}$ of aliquot was mixed with $1 \mathrm{ml}$ of Griess reagent (1 \% sulphanilamide, $2 \%$ o-phosphoric acid and $0.1 \%$ naphthyl ethylene diamine dihydrochloride) and absorbance was read at $546 \mathrm{~nm}$ and compared with the standard butylated hydroxyl toluene. The percentage inhibition activity was calculated using the formula; $\%$ inhibition $=\left(\right.$ Ao- $\left.\left.\mathrm{A}_{1}\right) / \mathrm{Ao}\right) \times 100$, where, Ao is the absorbance of the blank, $A_{1}$ is the absorbance of the leaf extract or standard.

DPPH radical scavenging activity $(\%)=\times 100$

Where Abs (control) : Absorbance of DPPH radical +methanol

Abs (sample): Absorbance ofDPPHradical+extract

\section{Statistical analysis:}

The data on $t$ were considered to calculate the mean $\pm \mathrm{SE}$ of each parameter and mean values of different groups were compared using one way ANOVA followed by Duncan's multiple range test and judged significant if $\mathrm{p}<0.05$.

\section{RESULTS AND DISCUSSION}

\section{Total phenolic and flavonoid content:}

The total phenolic and flavonoid content of leaf extract of LA was significantly higher than that of AS. The phenolic content of LA and AS was found to be $41.33 \pm 0.92 \mathrm{mg} / \mathrm{g}$ and $37.60 \pm 0.26 \mathrm{mg} / \mathrm{g}$, respectively. Similarly, the flavonoid content of leaf extracts of LA and AS was found to be $52.33 \pm 2.11$ and 38.96 $\pm 3.55 \mathrm{mg} / \mathrm{g}$, respectively.

\section{ABTS scavenging activity}

The Percent inhibition of ABTS radical generation by leaf extracts of LA and AS increased in a dosedependent manner with $\mathrm{IC}_{50}$ values of 503.07 and $543.63 \mu \mathrm{g} / \mathrm{ml}$, respectively. However, the ABTS radical 
scavenging activities of the two standards, gallic acid and ascorbic acid were higher than that of LA and AS with $\mathrm{IC}_{50}$ value of 416.2 and $410.66 \mu \mathrm{g} / \mathrm{ml}$, respectively (Figure 1). The extract of LA showed significantly higher ABTS scavenging activity at 500 and $600 \mu \mathrm{g} / \mathrm{ml}$ concentrations compared to that of AS.
The leaf extracts of LA and AS showed increasing DPPH free radical scavenging activity in a concentrationdependent manner with $\mathrm{IC}_{50}$ values of 229.56 and $270.24 \mu \mathrm{g} / \mathrm{ml}$, respectively. In comparison, the radical scavenging activities of the standards, gallic acid and ascorbic acid were higher than that of leaf extracts with

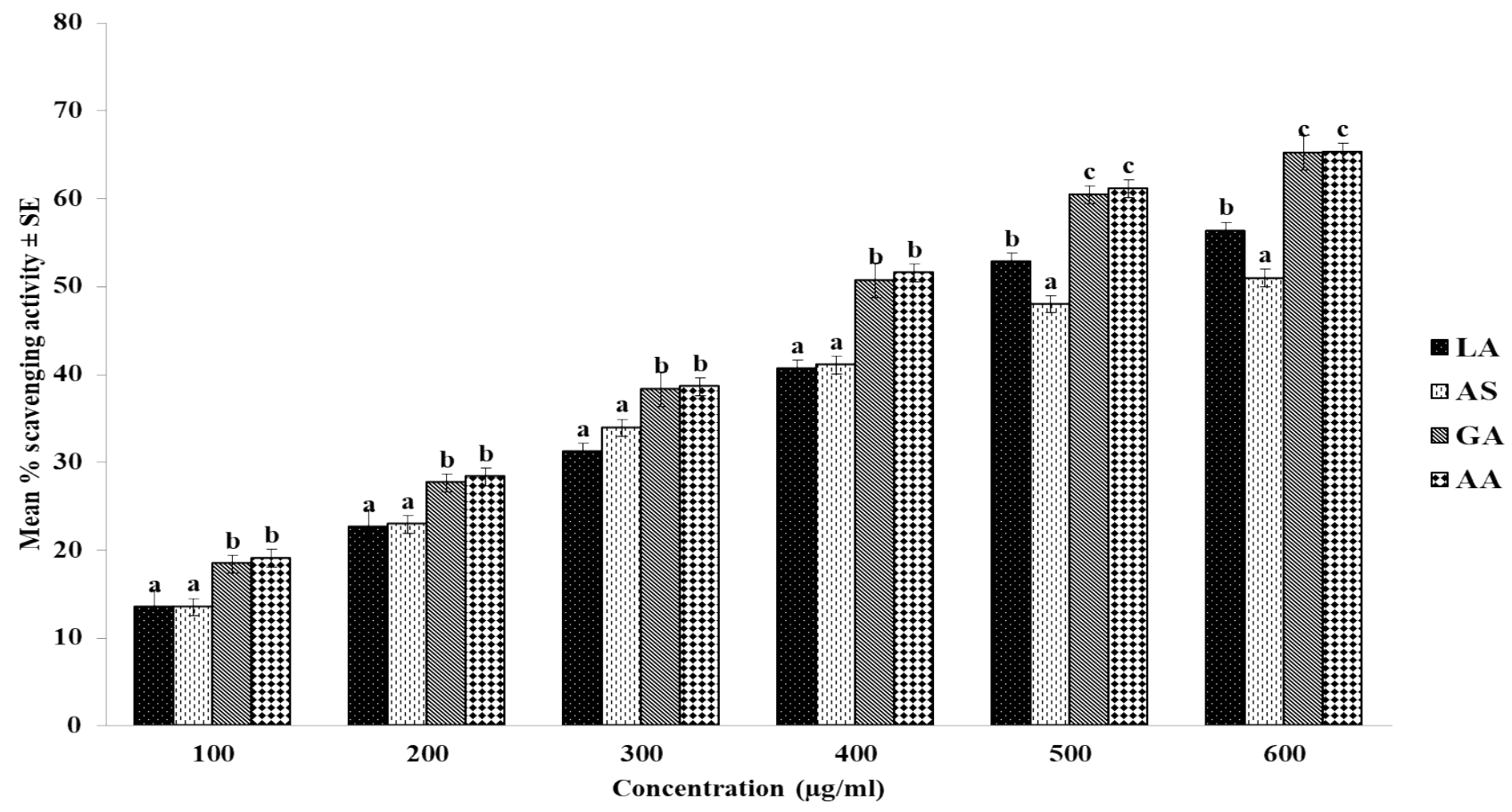

Figure 1: All values are mean \pm SE. Vertical bars graph showing ABTS radical scavenging activities of LA, AS, GA and AA groups. The higher radical scavenging activity in GA and AA groups compared with LA and AS.

Groups with same superscript letters do not significantly differ among themselves whereas those with different superscript letters significantly differ. LA-Lalit, AS-Allahabad safeda, GA-Gallic acid, AA-Ascorbic acid.

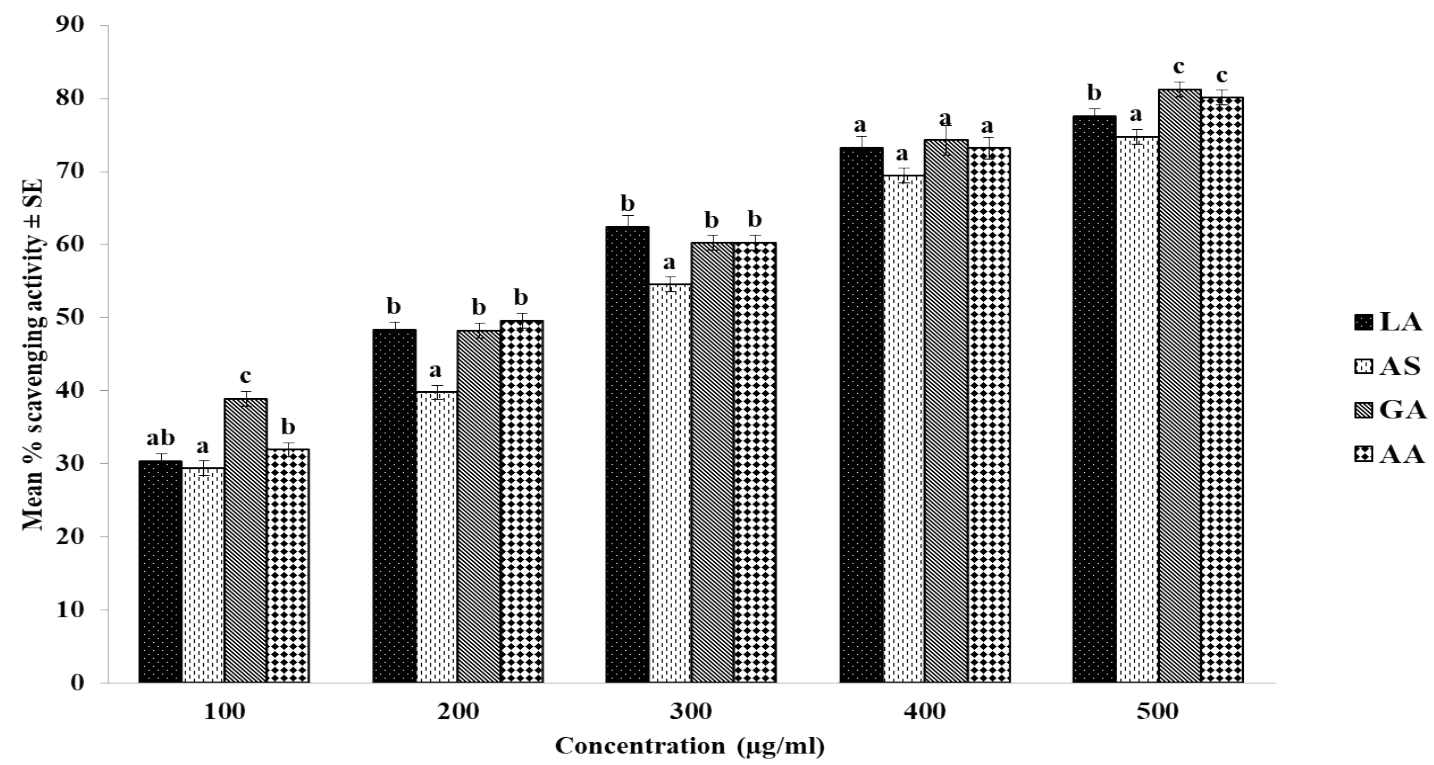

Figure 2: All values are mean \pm SE. Vertical bars graph showing DPPH radical scavenging activities of LA, AS, GA and AA groups. The higher radical scavenging activity in GA and AA groups compared with LA and AS. Groups with same superscript letters do not significantly differ among themselves whereas those with different superscript letters significantly differ. LA-Lalit, AS-Allahabad safeda, GA-Gallic acid, AA-Ascorbic acid. 


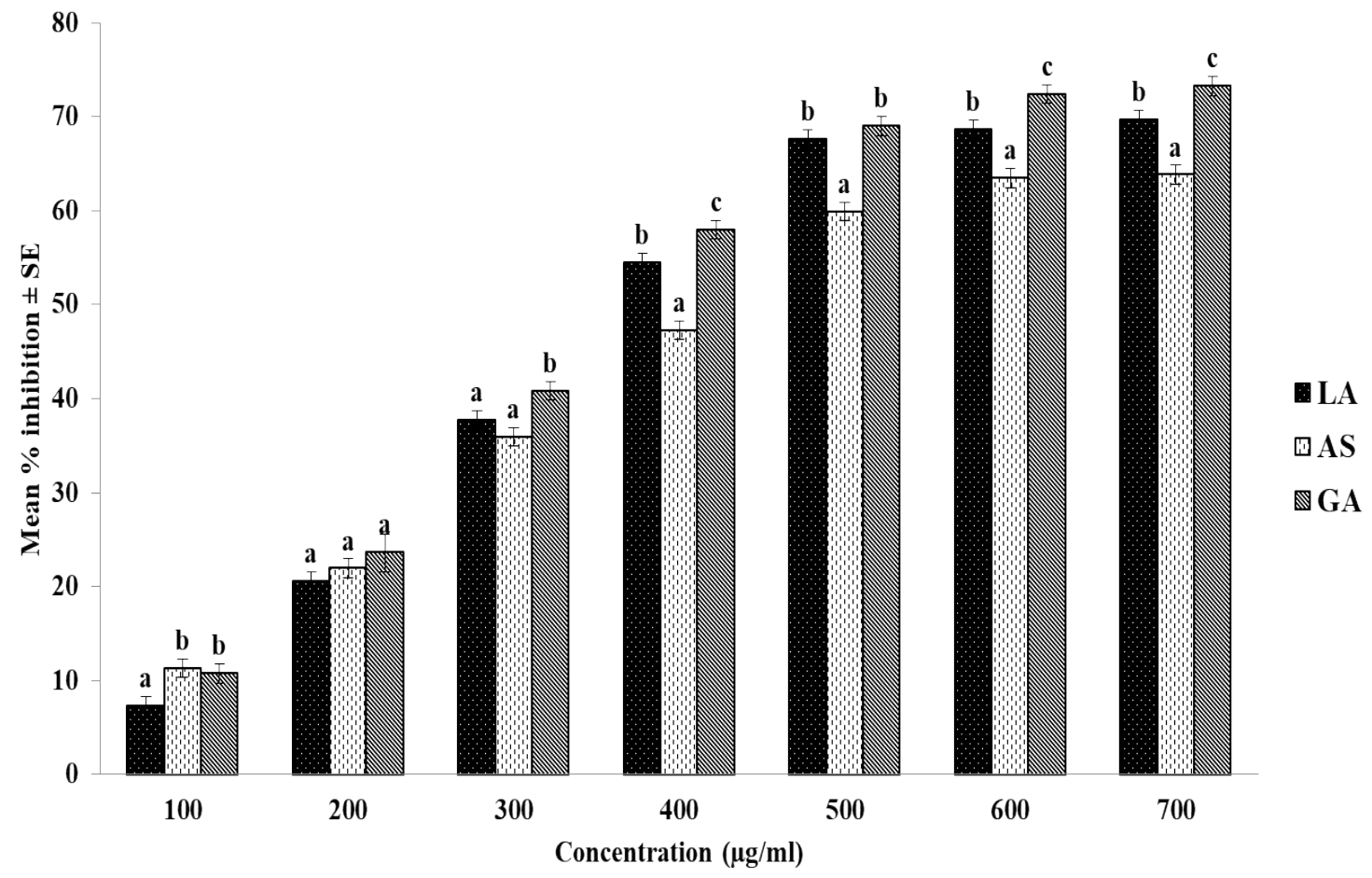

Figure 3: All values are mean \pm SE. Vertical bars graph showing nitric oxide radical scavenging activities of LA, AS and GA groups. Note the higher radical scavenging activity in GA compared with LA and AS. Groups with same superscript letters do not significantly differ among themselves whereas those with different superscript letters significantly differs. LA-Lalit, AS-Allahabad safeda, GA-Gallic acid.

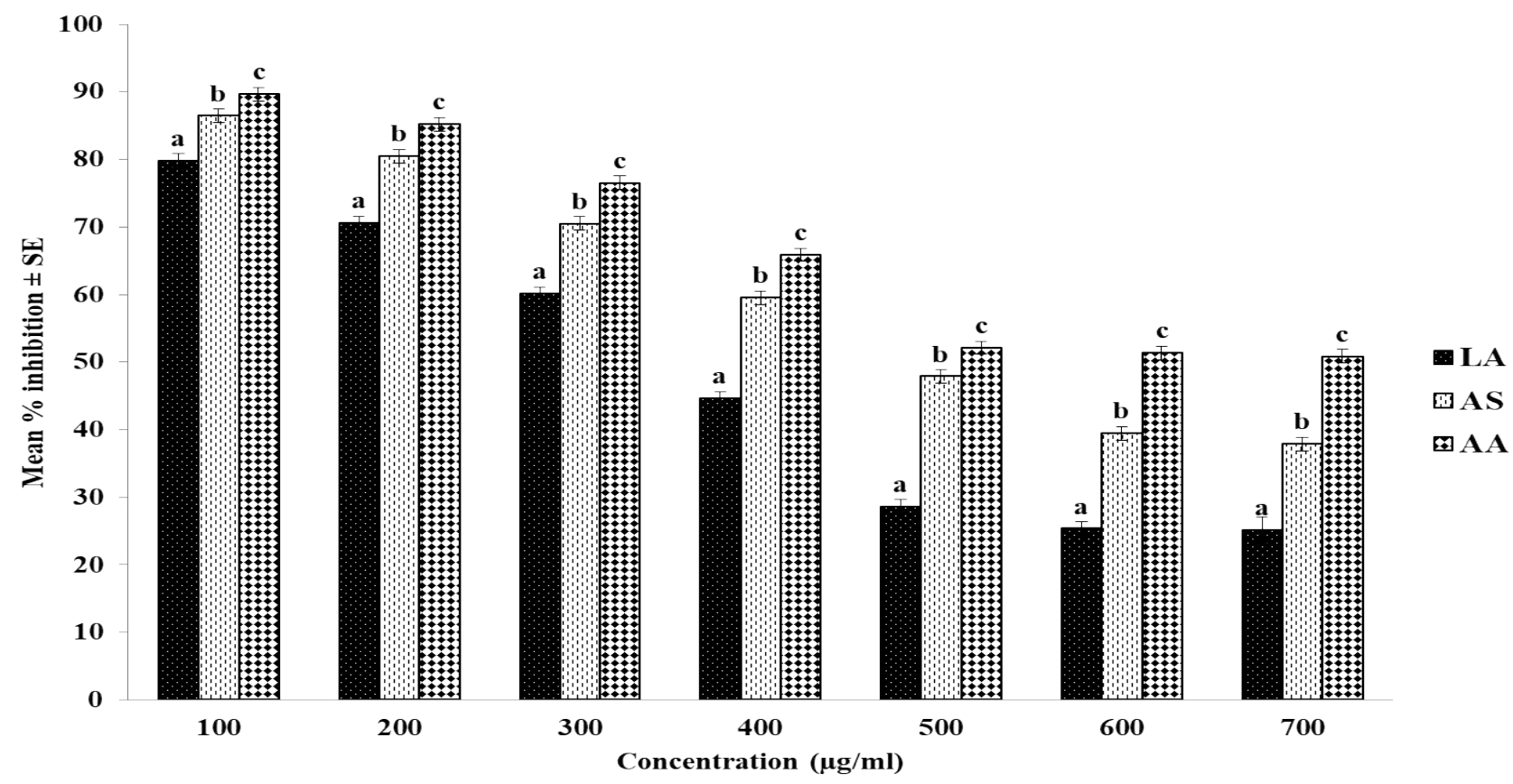

Figure 4: All values are mean \pm SE. Vertical bars graph showing super oxide radical scavenging activities of LA, AS and AA groups. The higher radical scavenging activity in AA compared with LA and AS. Groups with same superscript letters do not significantly differ among themselves whereas those with different superscript letters significantly differ. LA-Lalit, AS-Allahabad safeda, AAAscorbic acid.

$\mathrm{IC}_{50}$ values of 204.33 and $224.69 \mu \mathrm{g} / \mathrm{ml}$, respectively (Figure 2). The extract of LA showed significant increase in DPPH free radical scavenging activity at 200,300 and $500 \mu \mathrm{g} / \mathrm{ml}$ concentrations compared to that of AS. 


\section{Nitric oxide radical scavenging activity}

The percent inhibition of nitric oxide radical generation by leaf extracts of LA and AS increased in a dosedependent manner with $\mathrm{IC}_{50}$ values of 430.40 and $469.99 \mu \mathrm{g} / \mathrm{ml}$, respectively. However, the radical scavenging activity of the standard, gallic acid was higher than the extracts with $\mathrm{IC}_{50}$ values of $402.44 \mu \mathrm{g} /$ $\mathrm{ml}$ (73.26\% inhibition) (Figure 3$)$. The extract of LA produced greater $\%$ inhibition at 400, 500, 600 and 700 $\mu \mathrm{g} / \mathrm{ml}$ concentrations compared to that of AS.

The percentage inhibition of superoxide radical generation by LA and AS was decreased in concentration-dependent manner with $\mathrm{IC}_{50}$ values of 377.96 and $515.5 \mu \mathrm{g} / \mathrm{ml}$, respectively. However, the radical scavenging activity of the standard, ascorbic acid was higher than the extracts with a $\mathrm{IC}_{50}$ value of $612.80 \mu \mathrm{g} / \mathrm{ml}$ (50.1\% inhibition) (Figure 4).

\section{DISCUSSION}

The present investigation clearly demonstrated that the antioxidant potential of leaf extracts of LA and AS through inhibition of generation of free radicals in vitro. The reactive oxygen species (ROS) such as superoxide and hydroxyl radicals, hydrogen peroxide and singlet oxygen are often generated as products of biological reactions and damage the cells when present in excess ${ }^{[27]}$. Cellular antioxidant system scavenges the ROS and protects the system from their deleterious effects. The balance between oxidant and antioxidant system is maintained by both enzymatic and nonenzymatic mechanisms.

Herbal extracts and constituents isolated from herbs are rich source of antioxidants. Several plants, Cocculus hirsutus, Withania somnifera, Zingiber officinale, Azardirachta indica, Benincasa hispida, Sonchus asper, Momordica charantia were used as antioxidants ${ }^{[28,29]}$. It is evident from the present study that leaf extract of LA and AS were good source of antioxidants. LA showed higher phenolic and flavonoid content compared to that of AS. Polyphenols and flavonoids are significant free radical scavengers ${ }^{[30]}$.

Further, the study demonstrates the antioxidant property of the leaf extracts of LA and AS, it is due to the combined effects of different antioxidant mechanisms. Both the extracts showed significant ABTS and DPPH scavenging activity in a dose-dependent manner. The DPPH method is a stable free radical system and a sensitive way to determine the in vitro antioxidant activity of plant extracts ${ }^{[31]}$. The antioxidants efficacy is associated with their scavenging ability of stable free radicals. The leaf extract of LA showed higher free radical scavenging activity compared to that of AS. The DPPH assay suggests that the extracts of $P$. guajava are capable of donating hydrogen to a free radical in order to remove odd electron, which is responsible for the radical's reactivity.

Reduction of molecular oxygen into water generates super oxide anion radicals. It is an oxygen-centered radical with selective reactivity and produced by a number of auto-oxidation reactions. In addition, super oxides are also formed by activated phagocytes. Superoxide dismutase is antioxidant enzyme in the living cells which scavenges super oxide anion. In the present study, leaf extract of LA showed higher superoxide radical scavenging activity in a dosedependent manner compared to AS. The inhibition of generation of superoxide radicals is the probable mechanism of its scavenging activity.

Nitric oxide is another free radical, which acts as a pleiotropic inhibitor of physiological processes and reacts with superoxide anion radical to form a cytotoxic oxidant molecule, peroxynitrite (ONOO-). In the present investigation, LA effectively scavenged the nitric oxide radicals compared to AS and exhibited concentrationdependent scavenging activity. The study clearly revealed that the leaf extract of LA was more effective than AS since ABTS, DPPH, nitric oxide and superoxide radical scavenging activities of LA were significantly greater than AS. This was further confirmed with the presence of more phenolic and flavonoid contents in the leaf extract of LA than AS. Phenolic compounds directly contribute to antioxidant action of the natural substances. It is reported that phenolic compounds have inhibitory effects on mutagenesis and carcinogenesis in humans ${ }^{[32]}$ and polyphenols are potential protecting agents against lethal effects of oxidative stress. In the present investigation, the leaf extract of LA had the highest phenolic content concomitant with high free radical scavenging action. Hence, high antioxidant potential of LA extract might be due to the presence of more phenolic content.

Thus, present study clearly demonstrated that ethanol leaf extract of LA and AS is a source of potent antioxidant compounds, though LA was found to be more effective than AS. The extracts exerted actions by inhibiting generation of free radicals or scavenging those as shown by the in vitro assays. However, the active components 
responsible for these activities are unclear. Therefore, the present study provided an impetus to isolate and identify those antioxidant molecules of the leaf of LA and AS to study further potential benefits of these in treating different disorders.

\section{Acknowledgements:}

The first author acknowledges, Government of Karnataka, Department of Backward Classes Welfare for providing scholarship for the research purpose.

\section{REFERENCES}

1. Ramkumar KM, Rajaguru P, Ananthan R. Antimicrobial properties and phytochemical constituents of an antidiabetic plant Gymnema montanum. Adv Biol Resh 2007;1(1-2):67-71.

2. Erasto P, Grierson DS, Afolayan AJ. Evaluation of antioxidant activity and the fatty acid profile of the leaves of Vernonia amygdalina growing in South Africa. Food Chem 2007;104:636-42.

3. Thaipong K, Boonprakob, Crosby K, Cisneros-zevallos L, Hawkins D. Comparison of ABTS, DPPH, FRAP, and ORAC assays for estimating antioxidant activity from guava fruit extracts. J Food Composit Anal 2006;19:669-75.

4. Namiki M. Antioxidant Antimutagens in Food. Critic Rev Food Sci Nutr 1990;29:273-300.

5. Kasote DM, Katyare SS, Hegde MV, Bae H. Significance of antioxidant potential of plants and its relevance to therapeutic applications. Int J Biol Sci 2015;11(8):982-91.

6. Scalbert A, Williamson G. Dietary intake and bioavailability of Polyphenols. J Neutraceuticals Food Sci 2000;30:2073-2085.

7. Praveen K, Ramamurthy, Bon A: Antioxidant activity, total phenolic and flavonoid content of Morinda citrifolia fruit extract from various extraction processes. J Eng Sci Technol 2007;2(1):70-80.

8. Bergman M, Varshavsky L, Gottlieb HE. The antioxidant activity of aqueous spinach extract: chemical identification of active fractions. Phytochemistry 2001;58(1):143-52.

9. Sahreen S, Khan MR, Khan RA. Evaluation of antioxidant activities of various solvent extracts of Carissa opaca fruits. Food Chem 2010;122(4):1205-11.

10. Lozoya X, Meckes M, Abou-Zaid MA, Tortoriello J, Nozzolillo C, Arnason JT. Quercetin glycosides in Psidium guajava L. leaves and determination of a spasmolytic principle. Arch Med Res 1994;25(1):11-15.

11. Tona L, Kambu K, Ngimbi N, Mesia K, Penge O, Lusakibanza $\mathrm{M}$, et al. Antiamoebic and spasmolytic activities of extracts from some antidiarrhoeal traditional preparations used in Kinshasa, Congo. Phytomedicine 2000;7(1):31-38.

12. Hui-Yin CL, Yuh-Charn, Chui-Lan H. Evaluation of antioxidant activity of aqueous extract of some selected nutraceutical herbs. Food Chem 2007;104(4):1418-1424.

13. Jaiarj $\mathrm{P}$, Khoohaswan $\mathrm{P}$, Wongkrajang $\mathrm{Y}$, Peungvicha $\mathrm{P}$, Suriyawong $\mathrm{P}$, Saraya MLS, et al. Anticough and antimicrobial activities of Psidium guajava Linn. leaf extract. J Ethnopharmacol 1999;67:203-12.
14. Sunagawa M, Shimada S, Zhang Z, Oonishi A, Nakamura $\mathrm{M}$, Kosugi T. Plasma insulin concentration was increased by long-term ingestion of guava juice in spontaneous non-insulindependent diabetes mellitus (NIDDM) rats. J Health Sci 2004;50(6):674-678.

15. Teixeira RO, Camparoto ML, Mantovani MS, Vicentini VEP. Assessment of two medicinal plants, Psidium guajava L and Achillea millefolium L. in in vitro and in vivo assays. Genetic Mol Biol 2003;26:551-555

16. Grover IS, Bala S. Studies on antimutagenic effects of guava (Psidium guajava) in Salmonella typhimurium. Mutation Res 1993;300:1-3.

17. Rodriguez RC, Cruz PH, Rios HG: Lectins in fruits having gastrointestinal activity their participation in hemagglunating property of Escherichia coli.0157.H7. Arch Med Res 2001;32:251-57.

18. Siddhuraju P, Manian S: The antioxidant activity and free radical scavenging capacity of dietary phenolic extract from horse gram (Macrotylomauni florum Lam.) Verde. seeds. Food Chem 2007;105:950-58.

19. Czinner E, Hagymazi K, Blazovics A, Kery A, Szoke E, Lemberkovics E. The in-vitro effect of Helichysiflos on microzomal lipid peroxidation. J Ethanopharmacol 2001;77:31-35

20. Tadhani MB, Patel VH, Subhash R. In vitro antioxidant activities of Stevia rebaudiana leaves and callus. J Food Composit Anal 2007;20:323-329.

21. Kaur C, Kapoor HC. Antioxidant activity and total phenolic content of some Asian vegetables. Int J Food Sci Technol 2002;37:153-161

22. Ordonez AAL, Gomez JD, Vattuone MA, Isla ML. Antioxidant activities of Sechium edule (Jacq.) Swart extracts. Food Chem 2006;97:452-58.

23. Re R, Pellegrini N, Proteggente A, Pannala A, Yang M, RiceEvans C. Antioxidant activity applying an improved ABTS radical cation decolorization assay. Free Radical Biol Med 1999;26(10):1231-37.

24. Blois MS. Antioxidant determinations by the use of a stable free radical nature. Rev Food Sci Nutr 1958;181:1199-1200.

25. Sreejayan N, Rao MNA. Nitric oxide scavenging by curcuminoids. J Pharm Pharmacol 1997;(49):105-07.

26. Nishikimi M, Appaji N, Yagi K. The occurrence of superoxide anion in the reaction of reduced phenazine metho sulfate and molecular oxygen. Biochem Biophys Res Commun 1972;46:849-54.

27. Ottolenghi A. Interaction of ascorbic acid and mitochondria lipids. Arch Biochem Biophys 1959;79:355-363.

28. Chirag PJ, Tyagi S, Halligudi N, Yadav J, Pathak S, Singh SP, et al. Antioxidant activity of herbal plants: a recent review. J Drug Discovery Ther 2013;1(8):1-8.

29. Proestos C, Lytoudi K, Mavromelanidou OK, Zoumpoulakis P, Sinanoglou VJ. Antioxidant capacity of selected plant extracts and their essential oils. Antioxidants 2013; 2:11-22

30. Archana D, Dixitha M, Santhy KS. Antioxidant and anti clastogenic potential of Piper longum L. Int J Appl Pharm $2015 ; 7: 1-4$. 
31. Prasad L, Khan TH, Jahangir T, Sultana S. Acorus calamus extracts and nickel chloride: prevention of oxidative damage and hyperprolif-eration response in rat kidney. Biol Trace Element Res 2006;113(1):77-92.
32. Tanaka M, Kuei CW, Nagashima Y, Taguchi T. Application of antioxidative Millard reaction products from histidine and glucose to sardineproducts. Nippon Suisan Gakkaishil 1998;54:1409-1414. 